\title{
ADUBAÇÃO NITROGENADA, DENSIDADE DE SEMEADURA E ESPAÇẢMENTO ENTRE FILEIRAS NA CULTURA DO MILHO EM SISTEMA PLANTIO DIRETO ${ }^{1}$
}

\author{
Nitrogen fertilization, sowing rate and interrow spacing in \\ corn crop in no-tillage system
}

\author{
Martin Reinaldo Gross ${ }^{2}$, Renzo Garcia Von Pinho ${ }^{3}$, André Humberto de Brito ${ }^{4}$
}

\begin{abstract}
RESUMO
Entre as práticas e técnicas empregadas para obtenção de maior produtividade de milho, a escolha do arranjamento de plantas e a época de aplicação da cobertura nitrogenada estão entre as decisões mais importantes, associados a escolha da cultivar e sistema de cultivo. Objetivou-se com este trabalho, estudar em sistema plantio direto, a influência de quatro épocas de aplicação da adubação nitrogenada, associadas a três densidades de semeadura e dois espaçamentos entre fileiras, para duas cultivares na Região Sul de Minas Gerais. No local foram instalados dois experimentos em sistema plantio direto, sendo o primeiro instalado com o espaçamento de 0,45 $\mathrm{m}$ e o segundo espaçamento com $0,90 \mathrm{~m}$. Em cada experimento foram causas de variação: duas cultivares de milho (P 30K75 e TORK),

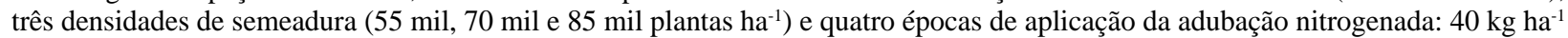
de $\mathrm{N}^{1}$ aplicados por ocasião da semeadura, sem nenhuma cobertura nitrogenada; $40 \mathrm{~kg} \mathrm{ha}^{-1}$ de $\mathrm{N}$ na semeadura $+120 \mathrm{~kg}$ ha ${ }^{-1}$ de $\mathrm{N}$ aplicados em cobertura logo após a semeadura; $40 \mathrm{~kg} \mathrm{ha}^{-1} \mathrm{de} \mathrm{N}$ na semeadura $+60 \mathrm{~kg} \mathrm{ha}^{-1} \mathrm{de} \mathrm{N}$ em cobertura no estádio de 4 a 5 folhas + $60 \mathrm{~kg} \mathrm{ha}^{-1}$ de $\mathrm{N}$ em cobertura no estádio de 7 a 8 folhas; $40 \mathrm{~kg} \mathrm{ha}^{-1}$ de $\mathrm{N}$ na semeadura $+120 \mathrm{~kg} \mathrm{ha}^{-1}$ de $\mathrm{N}$ em cobertura no estádio de 6 a 7 folhas. A adubação nitrogenada feita em cobertura, em uma aplicação ou dividida em duas, influi na altura de plantas, na altura de inserção da espiga e proporciona incremento significativo na produtividade de grãos de milho.
\end{abstract}

Termos para indexação: Zea mays, densidade de semeadura, espaçamentos entre linhas, plantio direto, adubação nitrogenada.

\begin{abstract}
Among the practices and techniques employed for obtaining increased corn yield, the choice of plant arrangement and time of nitrogen topdressing are among the most important, associated with the choice of the hybrid and cropping system. The objective of this trial was study in no-tillage system, the influence of four times of application of nitrogen fertilization associated with three sowing rates and two interrow spacings for two corn cultivars in south Minas Gerais. On the site, two experiments in no-tillage system were established, the first one being set up with the spacing of $0.45 \mathrm{~m}$ and the second spacing of $0.90 \mathrm{~m}$. In each experiment, two corn cultivars (P 30K75 and TORK), three sowing rates (55 thousand, 70 thousand and 85 thousand plants ha ${ }^{-1}$ ) and four times of application of nitrogen fertilization: $40 \mathrm{~kg} \mathrm{ha}^{-1}$ of $\mathrm{N}$ applied on the occasion of sowing without any nitrogen topdressing; $40 \mathrm{~kg}$ ha${ }^{1}$ of $\mathrm{N}$ at sowing $+120 \mathrm{~kg} \mathrm{ha}^{-1}$ of $\mathrm{N}$ topdressed soon after sowing; $40 \mathrm{~kg} \mathrm{ha}^{-1}$ of $\mathrm{N}$ at sowing $+60 \mathrm{~kg} \mathrm{ha}^{-1}$ of $\mathrm{N}$ topdressed at the stage of 4 to 5 leaves $+60 \mathrm{~kg} \mathrm{ha}^{-1}$ of $\mathrm{N}$ topdressed at the stage of 7 to 8 leaves, $40 \mathrm{~kg} \mathrm{ha}^{-1}$ of $\mathrm{N}$ at sowing $+120 \mathrm{~kg} \mathrm{ha}^{-1}$ of $\mathrm{N}_{\text {topdressed at }}$ the stage of 6 to 7 leaves. Nitrogen fertilization done into covering, in one or two applications influences in the height of the plants, the height of insertion of the ear and provides significant increases in corn grain yield.
\end{abstract}

Index terms: Zea mays, sowing rate, interrow spacings, no tillage planting, nitrogen fertilization.

(Recebido para publicação em 15 de julho de 2005 e aprovado em 19 de outubro de 2005)

\section{INTRODUÇÃO}

Com uma agricultura voltada ao manejo sustentável do solo tem-se notado aumento das práticas conservacionistas do solo, sendo uma delas o plantio direto. O plantio direto da cultura do milho é uma realidade na Região do Sul de Minas Gerais e um aspecto importante no sistema, refere-se ao manejo da adubação nitrogenada.

O nitrogênio é um dos nutrientes que apresenta os efeitos mais espetaculares no aumento da produção de grãos na cultura do milho. Tem grande importância como constituinte de moléculas de proteínas, enzimas, coenzimas, ácidos nucléicos e citocromos, além de sua importante função como integrante da molécula de clorofila (BULL \& CANTARELLA, 1993). Atualmente, discute-se muito sobre a época de aplicação do $\mathrm{N}$ na cultura do milho e mesmo sobre a necessidade do parcelamento quando de sua aplicação. França et al. (1994) relataram que o parcelamento indiscriminado do $\mathrm{N}$, sem levar em consideração fatores como produtividade esperada, demanda da cultura, textura do solo e outros, pode comprometer os efeitos da adubação.

Yamada (1995) citou que a adubação nitrogenada tem boa probabilidade de respostas ao uso de 30-40 $\mathrm{kg} \mathrm{ha}^{-1}$

\footnotetext{
${ }_{1}$ Parte da Dissertação apresentada à Universidade Federal de Lavras para obtenção do título de Mestre.

${ }^{2}$ Engenheiro Agrônomo, M.Sc. Fitotecnia/UFLA - Fundação Bahia - Av. Ahylon Macêdo, 11 - 47806-180 - Barreiras, BA - martingross@bol.com.br

${ }_{3}^{3}$ Professor Adjunto do Departamento de Agricultura da Universidade Federal de Lavras/UFLA - Cx. P. 3037 - $37200-000$ - Lavras, MG - renzo@ufla.br

${ }^{4}$ Engenheiro Agrônomo, Estudante de Pós-Graduação-Universidade Federal de Lavras/UFLA-Cx. P. 3037-37200-000-Lavras, MG-andrehbrito@yahoo.com.br
} 
de $\mathrm{N}$ na adubação de semeadura, com cobertura nitrogenada feita logo após a semeadura e sendo recomendável uma segunda cobertura em solos de textura mais arenosa, visando assim, menores perdas e conseqüentemente maior disponibilidade de $\mathrm{N}$ para as plantas. Borges (2003), trabalhando com solos de textura argilosa e de textura média, concluiu que em ambos as classes do solo a antecipação da cobertura nitrogenada logo após a semeadura proporciona produtividade de grãos semelhantes às obtidas quando esta é aplicada em outros estádios fenológicos do milho.

Entre outras práticas e técnicas empregadas para a obtenção da maior produtividade de milho, a escolha da densidade ideal de semeadura e do melhor arranjamento de plantas, seriam as melhores opções. Em função disso é que se procura diminuir os espaçamento entre linhas para a cultura do milho e aumentar a quantidade de plantas por área, buscando aumentar a produção de grãos.

As várias alternativas de combinações de espaçamentos e densidades de semeadura podem se definir como "arranjamento de plantas", ou seja, é a forma de como as plantas estão distribuídas na área, o espaçamento entre fileiras e a distribuição de plantas na linha. Teoricamente o melhor arranjamento de plantas é aquele que proporciona uma distribuição mais uniforme das plantas na linha de semeadura, possibilitando melhor utilização da luz, água e nutrientes (RIZZARDI et al., 1994). Utilizando os espaçamentos entre linhas de $0,40,0,60$ e $0,80 \mathrm{~m}$ e três densidades de semeadura 40,60 e 80 mil plantas ha ${ }^{-1}$, Penariol et al. (2002), pôde verificar que o espaçamento entre linhas de $0,40 \mathrm{~m}$ foi o mais produtivo tanto nas safrinhas de 2000 e 2001, quanto na safra de 2000/01 e a densidade de 80 mil plantas ha ${ }^{-1}$ foi mais produtiva na safrinha de 2001 e na safra de 2000/01.

Em estudos de espaçamento entre linhas, densidade de plantas e época de aplicação de adubação nitrogenada em milho, observa-se freqüentemente resultados contraditórios, assim é necessário pesquisas mais conclusivas sobre esses assuntos.

Objetivou-se com este trabalho estudar em sistema plantio direto, a influência de quatro épocas de aplicação da adubação nitrogenada, associadas a três densidades de semeadura (55 mil, 70 mil e 85 mil plantas ha $\left.{ }^{-1}\right)$ e dois espaçamentos entre linhas $(0,45 \mathrm{~m}$ e $0,90 \mathrm{~m}$ ), em características agronômicas de duas cultivares de milho.

\section{MATERIAL E MÉTODOS}

Foram utilizados dois híbridos comerciais com diferentes características (Tabela 1).

Os experimentos foram conduzidos na área experimental do Departamento de Agricultura da Universidade Federal de Lavras (DAG/UFLA), no município de Lavras, Região Sul do Estado de Minas Gerais.

Os experimentos sob sistema plantio direto foram instalados em Latossolo Vermelho Ácrico, textura argilosa ( $430 \mathrm{~g} \mathrm{~kg}^{-1}$ de argila).

A condução dos experimentos deu-se em período de ocorrência de temperaturas, intensidade e distribuição de chuvas favoráveis ao cultivo do milho (Figura 1).

No local foram instalados dois experimentos em sistema plantio direto, onde o primeiro foi instalado considerando o espaçamento de $0,45 \mathrm{~m}$ e o segundo no espaçamento de $0,90 \mathrm{~m}$. Em cada experimento foram causas de variação: duas cultivares de milho (P 30K75 e TORK), três densidades de semeadura (55 mil, 70 mil e 85 mil plantas $\mathrm{ha}^{-1}$ ) e quatro épocas de aplicação da adubação nitrogenada, definidas a seguir:

1) $40 \mathrm{~S}+0 \rightarrow 40 \mathrm{~kg} \mathrm{ha}^{-1}$ de $\mathrm{N}$ aplicados por ocasião da semeadura no sulco de semeadura (S), sem nenhuma cobertura nitrogenada $(0)$;

2) $40 \mathrm{~S}+120 \mathrm{AS} \rightarrow 40 \mathrm{~kg} \mathrm{ha}^{-1}$ de $\mathrm{N}$ na semeadura (S) $+120 \mathrm{~kg} \mathrm{ha}^{-1}$ de $\mathrm{N}$ aplicados em cobertura, logo após a semeadura (AS);

3) $40 \mathrm{~S}+60(4-5 \mathrm{~F})+60(7-8 \mathrm{~F}) \rightarrow 40 \mathrm{~kg} \mathrm{ha}^{-1} \mathrm{de} \mathrm{N}$ na semeadura (S) $+60 \mathrm{~kg} \mathrm{ha}^{-1}$ de N em cobertura, no estádio de 4 a 5 folhas $(4-5 \mathrm{~F})+60 \mathrm{~kg} \mathrm{ha}^{-1}$ de $\mathrm{N}$ em cobertura, no estádio de 7 a 8 folhas $(7-8 \mathrm{~F})$;

4) $40 \mathrm{~S}+120(6-7 \mathrm{~F}) \rightarrow 40 \mathrm{~kg} \mathrm{ha}^{-1}$ de N na semeadura (S) $+120 \mathrm{~kg} \mathrm{ha}^{-1}$ de $\mathrm{N}$ em cobertura, no estádio de 6 a 7 folhas (6-7 F).

$\mathrm{O}$ adubo nitrogenado uréia foi utilizado como fonte de N. As adubações nitrogenadas de cobertura foram realizadas manualmente, a $20 \mathrm{~cm}$ das fileiras de plantas e incorporadas a $3,0 \mathrm{~cm}$ de profundidade.

Para todos os experimentos foram utilizados $500 \mathrm{~kg}$ ha $^{-1}$ da fórmula 8: $28: 16$ mais $0,5 \%$ de zinco.

No estádio de 5 a 6 folhas totalmente expandidas, todas as parcelas dos dois experimentos receberam também $80 \mathrm{~kg} \mathrm{ha}^{-1}$ de $\mathrm{K}_{2} \mathrm{O}$ na forma de cloreto de potássio.

A semeadura foi realizada manualmente no dia 30/11/ 2003, sendo realizado o desbaste quando as plantas apresentavam três a quatro folhas totalmente expandidas, deixando-se o número de plantas por metro linear conforme a densidade de semeadura avaliada (55, 70 e 85 mil plantas ha $\left.{ }^{-1}\right)$.

Ciênc. agrotec., Lavras, v. 30, n. 3, p. 387-393, maio/jun., 2006 
TABELA 1 - Características dos híbridos utilizados.

\begin{tabular}{ccccc}
\hline Cultivares & Base genética & Ciclo & Grão & Porte \\
\hline P 30K75 & Híbrido simples & Semi Precoce & Duro & Baixo/médio \\
TORK & Híbrido simples & Precoce & Duro & Baixo/médio \\
\hline
\end{tabular}

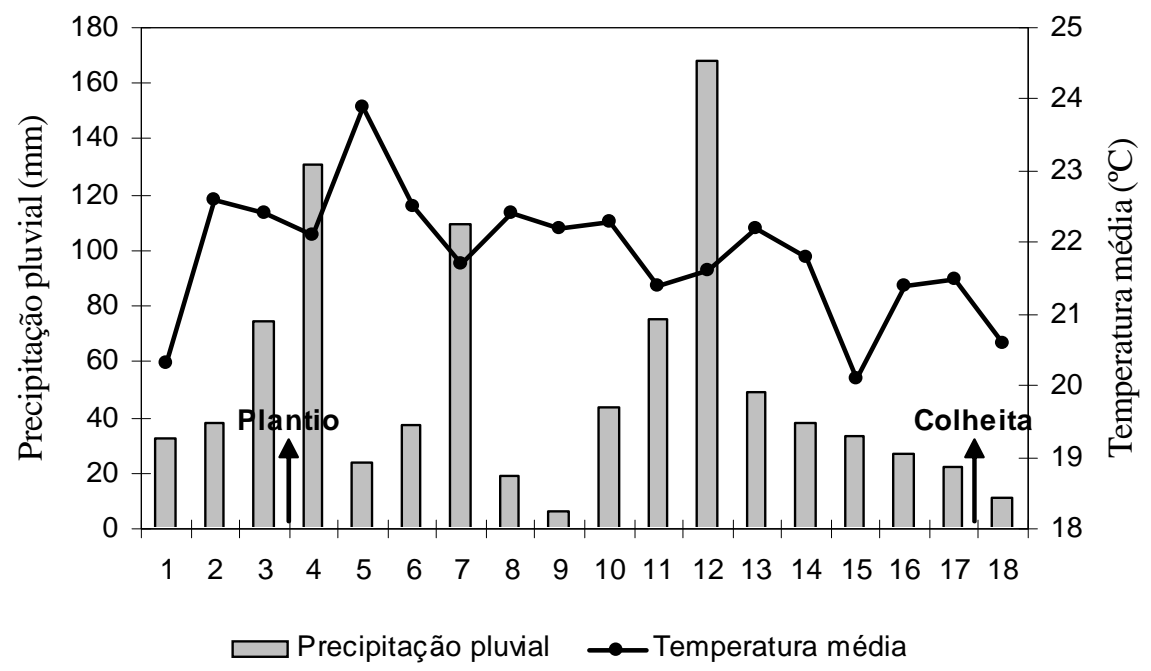

FIGURA 1 - Dados médios de temperatura e precipitação pluvial por decêndio, em Lavras, MG, de 01/11/2003 a 28/04/2004. Dados obtidos no setor de Bioclimatologia da UFLA, Lavras/MG, 2005.

Cada experimento foi conduzido sob o delineamento experimental de blocos casualizados em esquema fatorial $2 \times 3 \times 4$, com três repetições, sendo as duas cultivares, as três densidades de semeaduras e as quatro épocas de aplicações da adubação nitrogenada. A parcela experimental foi constituída de quatro fileiras de $5 \mathrm{~m}$ de comprimento e $a$ área útil foi as duas fileiras centrais, onde foram coletados todos os dados experimentais antes e durante a colheita.

Foram avaliadas no trabalho as seguintes características: altura de plantas, altura de inserção de espigas, produtividade de grãos e porcentagem de plantas acamadas e quebradas.

Inicialmente foi realizada uma análise de variância individual para cada experimento (espaçamentos) e posteriormente um análise conjunta envolvendo os dois espaçamentos.

Todas as análises estatísticas foram realizadas utilizando-se o programa estatístico SISVAR (FERREIRA, 2000). Os dados obtidos, após serem submetidos à análise de variância e quando verificadas diferenças estatísticas, foram submetidos a teste de médias ou análises de regressão. Aplicou-se teste de médias (Scott-Knott, a 5\% de probabilidade) quando as variáveis avaliadas foram de natureza qualitativa (cultivar, época de aplicação do $\mathrm{N} \mathrm{e}$ espaçamentos) e análise de regressão quando as variáveis foram de natureza quantitativa (densidade de plantas).

\section{RESULTADOS E DISCUSSÃO}

Na Tabela 2 estão apresentados os dados relativos ao efeito dos espaçamentos sobre a altura de plantas. No espaçamento de $0,90 \mathrm{~m}$ obteve-se uma maior altura de planta que o de 0,45 m. Esse resultado concorda com o obtido por Manfron (1985) que, avaliando os espaçamentos de $0,70 \mathrm{~m}, 0,90 \mathrm{~m}$ e $1,10 \mathrm{~m}$, encontrou as maiores alturas de planta, no maior espaçamento. Resende (2003), utilizando os espaçamentos de $0,45 \mathrm{~m}, 0,70 \mathrm{~m}$ e $0,90 \mathrm{~m}$ obteve resultados semelhantes.

Na Tabela 3, encontram-se as médias de altura de plantas em função das épocas de aplicação da cobertura nitrogenada. Para a cultivar TORK ocorreu diferença significativa para a altura de plantas, considerando as épocas de aplicação da cobertura nitrogenada. As maiores médias ocorreram quando foram realizadas duas aplicações com 4-5 folhas e 7-8 folhas ou quando toda a cobertura foi aplicada 
quando a planta estava com 6-7 folhas. Para a cultivar P 30K75 também houve diferença significativa, tendo a menor média de altura de planta sido obtida no tratamento com ausência de aplicação da adubação de cobertura e a maior, quando a adubação de cobertura foi feita após o plantio, quando a planta estava com 6-7 folhas. Houve diferença significativa entre as cultivares somente quando as adubações de cobertura foram feitas após a semeadura (duas aplicações com 4-5 folhas e 7-8 folhas e quando a planta estava com 6-7 folhas).

Quanto à altura de plantas, a cultivar TORK mostrou maior altura de inserção de espigas que a cultivar P 30K75 (Tabela 4). Esse resultado contraria os obtidos por Oliveira (1989) que observou que cultivares mais tardias apresentam maior altura de inserção de espigas, quando comparadas a materiais mais precoces.

Os dados relativos aos efeitos da cobertura nitrogenada sobre altura de inserção de espigas são mostrados na Tabela 5. A maior média de altura de inserção espigas foi obtido no tratamento com a adubação de cobertura feita de uma só vez após a semeadura, quando a planta estava com 67 folhas e as menores médias com ausência de aplicação de adubação em cobertura e quando a adubação nitrogenada foi aplicada por ocasião da semeadura.
Há uma relação linear entre a porcentagem de plantas acamadas e quebradas com as densidades de plantas utilizadas, nos dois espaçamentos (Figura 2). No espaçamento de $0,45 \mathrm{~m}$ constatou-se que para um aumento de 1000 plantas ha ${ }^{-1}$, foi verificado um acréscimo de 0,198 unidade na porcentagem de plantas acamadas e quebradas. Pela equação obtida para o espaçamento de $0,90 \mathrm{~m}$ detectouse que, para um aumento de 1000 plantas ha ${ }^{-1}$, foi verificado um acréscimo de 0,31 unidade na porcentagem de plantas acamadas e quebradas.

Para o espaçamento de $0,45 \mathrm{~m}$ não ocorreu diferença na porcentagem de plantas acamadas e quebradas, nas diferentes épocas de aplicação da cobertura nitrogenada. No espaçamento de $0,90 \mathrm{~m}$, houve diferença significativa, e quando a adubação de cobertura foi feita dividida em duas aplicações, com 4-5 folhas e 7-8 folhas, ou tudo aplicado quando a planta estava com 6-7 folhas, a porcentagem de plantas acamadas e quebradas foi maior que nos demais tratamentos. Nos espaçamentos entre fileiras, houve apenas diferença significativa na porcentagem de plantas acamadas e quebradas para o tratamento no qual a adubação de cobertura foi feita em duas aplicações, com 4-5 folhas e 7-8 folhas (Tabela 6).

TABELA 2 - Médias de altura de plantas (m), em função de dois espaçamentos entre fileiras, considerando duas cultivares, três densidades de plantas e quatro épocas de aplicação da cobertura nitrogenada. UFLA, Lavras/MG, 2005.

\begin{tabular}{cc}
\hline Espaçamentos $(\mathbf{m})$ & Médias \\
\hline 0,90 & $2,00 \mathrm{a}$ \\
0,45 & $1,96 \mathrm{~b}$ \\
\hline
\end{tabular}

Médias seguidas de letras distintas diferem entre si, pelo teste " $F$ " $(\mathrm{P} \leq 0,05)$.

TABELA 3 - Médias de altura de plantas (m) de cultivares de milho em função de quatro épocas de aplicação da cobertura nitrogenada considerando dois espaçamentos entre linhas e três densidades de semeadura. UFLA, Lavras/MG, 2005.

\begin{tabular}{cccc}
\hline $\begin{array}{c}\text { Época de aplicação da cobertura } \\
\text { nitrogenada }\end{array}$ & TORK & P 30K75 & Médias \\
\hline $40 \mathrm{~S}+120(6-7 \mathrm{~F})$ & $2,11 \mathrm{aA}$ & $2,12 \mathrm{aB}$ & 2,12 \\
$40 \mathrm{~S}+60(4-5 \mathrm{~F})+60(7-8 \mathrm{~F})$ & $2,12 \mathrm{aA}$ & $2,02 \mathrm{bB}$ & 2,07 \\
$40 \mathrm{~S}+120 \mathrm{AS}$ & $1,88 \mathrm{bA}$ & $1,93, \mathrm{cA}$ & 1,91 \\
$40 \mathrm{~S}+0$ & $1,84 \mathrm{bA}$ & $1,82 \mathrm{dA}$ & 1,83 \\
\hline Médias & 1,99 & 1,97 & \\
\hline
\end{tabular}

Médias seguidas de letras distintas minúsculas na coluna diferem entre si, pelo teste de Scott-Knott $(\mathrm{P} \leq 0,05)$.

Médias seguidas de letras distintas maiúsculas na linha diferem entre si, pelo teste " $F$ " $(\mathrm{P} \leq 0,05)$.

Ciênc. agrotec., Lavras, v. 30, n. 3, p. 387-393, maio/jun., 2006 
TABELA 4 - Médias de altura de inserção de espigas (m), em função de duas cultivares, considerando dois espaçamentos entre fileiras, três densidades de semeadura e quatro épocas de aplicação da cobertura nitrogenada. UFLA, Lavras/MG, 2005.

\begin{tabular}{cc}
\hline Cultivares & Médias \\
\hline TORK & $1,05 \mathrm{a}$ \\
P 30K75 & $1,01 \mathrm{~b}$ \\
\hline
\end{tabular}

Médias seguidas de letras distintas diferem entre si pelo teste " $\mathrm{F}$ " $(\mathrm{P} \leq 0,01)$.

TABELA 5 - Médias de altura de inserção da espigas (m), em função de quatro épocas de aplicação da cobertura nitrogenada, considerando dois espaçamentos entre fileiras, duas cultivares e três densidades de semeadura. UFLA, Lavras/MG, 2005.

\begin{tabular}{cc}
\hline Época de aplicação da cobertura nitrogenada & Médias \\
\hline $40 \mathrm{~S}+120(6-7 \mathrm{~F})$ & $1,14 \mathrm{a}$ \\
$40 \mathrm{~S}+60(4-5 \mathrm{~F})+60(7-8 \mathrm{~F})$ & $1,12 \mathrm{~b}$ \\
$40 \mathrm{~S}+120 \mathrm{AS}$ & $0,97 \mathrm{c}$ \\
$40 \mathrm{~S}+0$ & $0,90 \mathrm{c}$ \\
\hline
\end{tabular}

Médias seguidas de letras distintas diferem entre si, pelo teste de Scott-Knott $(\mathrm{P} \leq 0,05)$.

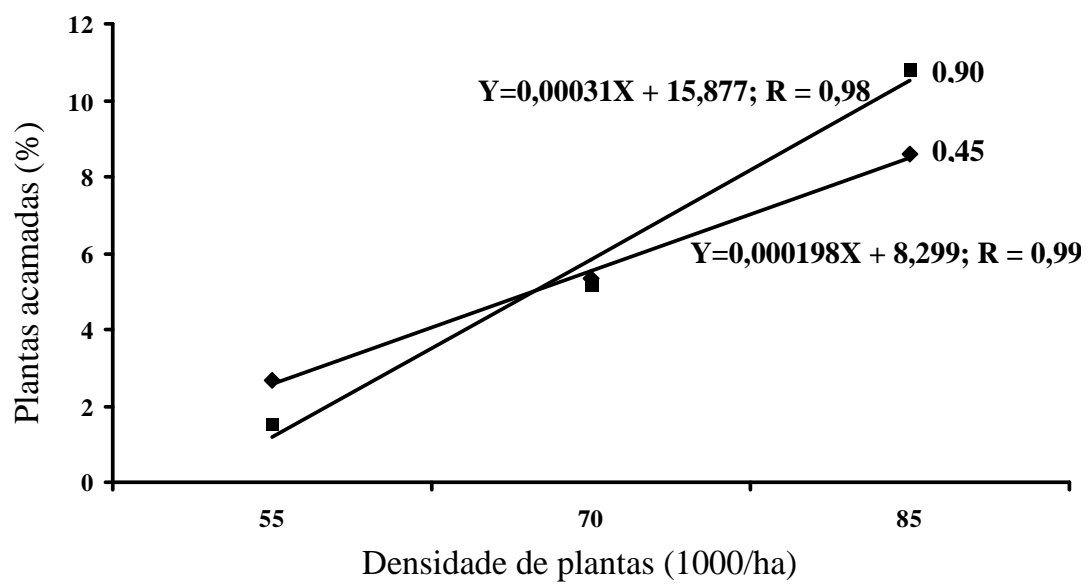

FIGURA 2 - Representação gráfica da equação de regressão para plantas acamadas e quebradas (\%), em função das densidades de semeadura, nos dois espaçamentos. UFLA, Lavras/MG, 2005.

TABELA 6 - Médias de plantas acamadas e quebradas (\%), em dois de espaçamento entre fileiras de milho, em função de quatro épocas de aplicação da cobertura nitrogenada, considerando duas cultivares e três densidades de semeadura. UFLA, Lavras/MG, 2005.

\begin{tabular}{cllc}
\hline Época de aplicação da cobertura nitrogenada & $\mathbf{0 , 4 5} \mathbf{~ m}$ & $\mathbf{0 , 9 0 ~} \mathbf{~}$ & Médias \\
\hline $40 \mathrm{~S}+120(6-7 \mathrm{~F})$ & $6,05 \mathrm{aA}$ & $7,16 \mathrm{aA}$ & 6,61 \\
$40 \mathrm{~S}+60(4-5 \mathrm{~F})+60(7-8 \mathrm{~F})$ & $4,48 \mathrm{aA}$ & $6,96 \mathrm{aB}$ & 5,72 \\
$40 \mathrm{~S}+120 \mathrm{AS}$ & $6,12 \mathrm{aA}$ & $4,89 \mathrm{bA}$ & 5,51 \\
$40 \mathrm{~S}+0$ & $5,49 \mathrm{Aa}$ & $4,34 \mathrm{bA}$ & 4,91 \\
\hline Médias & 5,54 & 5,84 & \\
\hline
\end{tabular}

Médias seguidas de letras distintas minúsculas na coluna, diferem entre si pelo teste de Scott-Knott $(\mathrm{P} \leq 0,05)$.

Médias seguidas de letras distintas, maiúsculas na linha, diferem entre si pelo teste " $\mathrm{F}$ " $(\mathrm{P} \leq 0,05)$.

Ciênc. agrotec., Lavras, v. 30, n. 3, p. 387-393, maio/jun., 2006 
No espaçamento de $0,45 \mathrm{~m}$, a menor produtividade foi obtida na ausência da cobertura nitrogenada; já no espaçamento de $0,90 \mathrm{~m}$, a menor produtividade foi obtida na ausência da cobertura nitrogenada e na adubação nitrogenada de cobertura feita por ocasião da semeadura. As maiores produtividades de grãos em ambos os espaçamentos foram obtidas nas adubações de cobertura feitas após a semeadura, isto é, duas aplicações de cobertura com 4-5 folhas e 7-8 folhas $(40 \mathrm{~S}+60(4-5 \mathrm{~F})+60$ $(7-8 \mathrm{~F}))$ e apenas uma aplicação com 6-7 folhas $(40 \mathrm{~S}+120$ (6-7F)). Entre os espaçamentos, houve diferença significativa na produtividade de grãos apenas no tratamento em que houve ausência de adubação nitrogenada em cobertura (Tabela 7).

Assim, nas condições ambientais em que foi realizado o trabalho, são inviáveis a não aplicação da cobertura nitrogenada e a aplicação de toda a cobertura nitrogenada por ocasião da semeadura. Esses dados diferem dos obtidos por Borges (2003), que verificou que a antecipação da cobertura nitrogenada para logo após a semeadura proporciona produtividades de grãos semelhantes às obtidas quando esta é aplicada em outros estádios fenológicos do milho. Vale ressaltar que, durante a condução dos experimentos de Borges (2003), as precipitações foram bem distribuídas e em intensidades suficientemente adequadas para o bom desenvolvimento da cultura do milho. Por outro lado, os resultados obtidos neste trabalho concordam com os de Souza (2002), que observou que a antecipação da adubação de cobertura na semeadura proporciona rendimentos menores que quando feita em uma ou parcelada em duas vezes no início do ciclo da cultura.

Não foram observadas diferenças significativas na produtividade de grãos entre as densidades de 55, 70 e 85 mil plantas ha-1 (Tabela 8). Resende (2003), avaliando três densidades de semeadura, 55, 70 e 90 mil plantas ha- $\mathrm{h}^{-1}$ em dois anos agrícolas, observou que, no ano agrícola de 2000/01, não houve diferenças de produtividade de grãos entre as densidades utilizadas, porém, no ano agrícola de 2001/02, as densidades de 70 e 90 mil plantas $\mathrm{ha}^{-1}$ foram as mais promissoras para produtividade de grãos.

Não foram encontradas diferenças significativas entre as cultivares TORK e 30K75 (Tabela 9).

Em estudos de espaçamento entre linhas, densidades de semeadura e época de aplicação de adubação nitrogenada em milho, observam-se, freqüentemente, resultados contraditórios e pouco conclusivos, pois, são acentuadamente afetados pelas condições ambientais.

TABELA 7 - Médias de produtividade de grãos $\left(\mathrm{kg} \mathrm{ha}^{-1}\right)$, em dois espaçamentos entre fileiras de milho (m), em função de quatro épocas de aplicação da cobertura nitrogenada, considerando duas cultivares e três densidade de semeadura. UFLA, Lavras/MG, 2005.

\begin{tabular}{cccc}
\hline $\begin{array}{c}\text { Época de aplicação da cobertura } \\
\text { nitrogenada }\end{array}$ & $\mathbf{0 , 4 5}$ & $\mathbf{0 , 9 0}$ & Médias \\
\hline $40 \mathrm{~S}+120(6-7 \mathrm{~F})$ & $8454 \mathrm{aA}$ & $8563 \mathrm{aA}$ & 8507 \\
$40 \mathrm{~S}+60(4-5 \mathrm{~F})+60(7-8 \mathrm{~F})$ & $8521 \mathrm{aA}$ & $7910 \mathrm{aA}$ & 8216 \\
$40 \mathrm{~S}+120 \mathrm{AS}$ & $5816 \mathrm{bA}$ & $5965 \mathrm{bA}$ & 5891 \\
$40 \mathrm{~S}+0$ & $4619 \mathrm{cB}$ & $5680 \mathrm{bA}$ & 5150 \\
\hline Médias & 6853 & 7030 & \\
\hline
\end{tabular}

Médias seguidas de letras distintas minúsculas na coluna, diferem entre si pelo teste de Scott-Knott $(\mathrm{P} \leq 0,05)$.

Médias seguidas de letras distintas maiúsculas na linha, diferem entre si pelo teste " $\mathrm{F}$ " $(\mathrm{P} \leq 0,05)$.

TABELA 8 - Médias de produtividade de grãos $\left(\mathrm{kg} \mathrm{ha}^{-1}\right)$, em função três densidade de semeadura, considerando dois espaçamentos entre fileiras, duas cultivares e quatro épocas de aplicação da cobertura nitrogenada. UFLA, Lavras/MG, 2005.

\begin{tabular}{cc}
\hline Densidades & Médias \\
\hline $55 \mathrm{mil}$ & $6659 \mathrm{a}$ \\
$70 \mathrm{mil}$ & $7142 \mathrm{a}$ \\
$85 \mathrm{mil}$ & $7022 \mathrm{a}$ \\
\hline
\end{tabular}

Médias seguidas de letras distintas diferem entre si, pelo teste teste de Scott-Knott $(\mathrm{P} \leq 0,05)$.

Ciênc. agrotec., Lavras, v. 30, n. 3, p. 387-393, maio/jun., 2006 
TABELA 9 - Médias de produtividade de grãos $\left(\mathrm{kg} \mathrm{ha}^{-1}\right)$, em função de duas cultivares, considerando dois espaçamentos entre fileiras, três densidades de semeadura e quatro épocas de aplicação da cobertura nitrogenada. UFLA, Lavras/MG, 2005.

\begin{tabular}{cc}
\hline Cultivares & Médias \\
\hline P 30K75 & $6954 \mathrm{a}$ \\
TORK & $6928 \mathrm{a}$ \\
\hline
\end{tabular}

Médias seguidas de letras distintas diferem entre si, pelo teste " $\mathrm{F}$ " $(\mathrm{P} \leq 0,05)$.

\section{CONCLUSÕES}

A produtividade de grãos não é influenciada pelas cultivares e densidades de semeadura.

Ocorre uma maior porcentagem de plantas acamadas e quebradas com o aumento da densidade de plantas.

A adubação nitrogenada feita em cobertura, em uma aplicação ou dividida em duas, influi na altura de plantas, na altura de inserção da espiga e proporciona incremento significativo na produtividade de grãos de milho.

\section{REFERÊNCIAS BIBLIOGRÁFICAS}

BORGES, I. D. Avaliação de épocas de aplicação de cobertura nitrogenada, fontes de nitrogênio e de espaçamentos entre linhas na cultura do milho. 2003. 73 p. Dissertação (Mestrado em Fitotecnia) - Universidade Federal de Lavras, Lavras, 2003.

BULL, L. T.; CANTARELLA, H. (Eds.). Cultura do milho: fatores que afetam a produtividade. Piracicaba: Potafós, 1993.

FERREIRA, D. F. SISVAR - Sistema de análise de variância. Versão 3.04. Lavras: UFLA, 2000.

FRANÇA, G. E.; COELHO, A. M.; RESENDE, M.; BAHIA FILHO, A. F. C. Parcelamento da adubação nitrogenada em cobertura na cultura do milho irrigado. In: CENTRO NACIONAL DE PESQUISA DE MILHO E SORGO. Relatório anual: 1992-1993. Sete Lagoas: EMBRAPA, 1994. p. 28-30.

MANFRON, P. A. Análise quantitativa do crescimento do cultivar AG 401 (Zea mays L.) sob diferentes sistemas de preparo do solo e população de plantas. 1985.120 p. Dissertação (Mestrado em Agrometeorologia) - Escola Superior de Agricultura Luiz de Queiroz, Piracicaba, 1985.

OLIVEIRA, M. D. X. Comportamento da cultura do milho (Zea mays L.) em diferentes épocas de semeadura nas regiões centro e norte de Mato Grosso do Sul. 1989. $90 \mathrm{f}$. Dissertação (Mestrado em Agronomia) - Escola Superior de Agricultura de Lavras, Lavras, 1989.

PENARIOL, F. G.; BORDIN, L.; COICEV, L.; FARINELLI, R.; FORNASIERI FO, D. Comportamento de genótipos de milho em função do espaçamento e da densidade de populacional nos períodos de safrinha e safra. In: CONGRESSO NACIONAL DE MILHO E SORGO, 24., 2002, Florianópolis, SC. Anais... Florianópolis: [s.n.], 2002.

RESENDE, S. G. Alternativas de espaçamentos entre fileiras e densidades de plantas no cultivo do milho. 2003. 55 p. Dissertação (Mestrado em Fitotecnia) - Universidade Federal de Lavras, Lavras, 2003.

RIZZARDI, M. A.; BOLLER, W.; DALLOGLIO, R. C. Distribuição de plantas de milho, na linha de semeadura, e seus efeitos nos componentes de produção.Pesquisa Agropecuária Brasileira, Brasília, v. 29, n. 8, p. 1231-1236, ago. 1994.

SOUZA, L. O. V. Sistemas de cultivo, épocas de semeadura e doses de nitrogênio na produção de grãos de milho. 2002. 44 p. Dissertação (Mestrado em Fitotecnia) - Universidade Federal de Lavras, Lavras, 2002.

YAMADA, T. Adubação nitrogenada do milho. Informações Agronômicas, Piracicaba, n. 71, p. 1-3, set. 1995. 